\title{
An In Vivo and In Vitro Evaluation of the Mutual Interactions between the Lung and the Large Intestine
}

\author{
Lei-Miao Yin, Guang-Quan Zhang, Xing-Ke Yan, Yu Wang, \\ Yu-Dong $\mathrm{Xu}$, and Yong-Qing Yang
}

Shanghai Research Institute of Acupuncture and Meridian, Shanghai University of Traditional Chinese Medicine, Shanghai 200030, China

Correspondence should be addressed to Yong-Qing Yang; yyq@shutcm.edu.cn

Received 25 May 2013; Accepted 28 June 2013

Academic Editor: Xiang-Yu Hou

Copyright (c) 2013 Lei-Miao Yin et al. This is an open access article distributed under the Creative Commons Attribution License, which permits unrestricted use, distribution, and reproduction in any medium, provided the original work is properly cited.

One of the most important theories of the traditional Chinese medicine is the exterior-interior relationship between the lung and the large intestine; so far, little direct experimental evidence has been reported to support such relationship. Here we for the first time investigated the mutual interactions between the lung and the large intestine by examining the relevancies between the pulmonary functions and the rectal resting pressure in the rat models of asthma and constipation. We also evaluated the effects of the lung homogenate and the large intestine homogenate on the isolated large intestine muscle strip and the isolated tracheal spiral, respectively. Our results showed that the pulmonary resistance and pulmonary compliance were closely related to the rectal resting pressure in the asthmatic rat model, while the rectal resting pressure was much correlated with the pulmonary resistance in the rat model of constipation. Moreover, it was shown that the lung homogenate could specifically contract the isolated large intestine muscle strip. Overall, this study provided new lines of evidence for the theory and highlighted the potential application in the treatment of the corresponding diseases.

\section{Introduction}

The theory of the "exterior-interior relationship between the lung and the large intestine" originates from the Yellow Emperor's Classic of Internal Medicine (Huang Di Nei Jing), which is one of the most important governing principles of traditional Chinese medicine in the clinical application [1]. According to the theory, the lung meridian communicates with the large intestine meridian, which creates an exteriorinterior relationship and influences each other specifically [2]. The lung diseases affect the condition of the large intestine except for the symptoms of nose and throat, while the disturbances of the large intestine could cause the pulmonary and bronchial dysfunctions. The lung is the essential respiration organ while the large intestine absorbs water and passes the wastes out of the body; obviously the two organs are anatomically separated; however, there are several aspects of evidence for the special relationship between the lung and the large intestine in both physiology and pathology.
The possibility of the mutual interaction between the lung and the large intestine was demonstrated by the same origin, the interactive pathophysiologic relationship, and the common effectors molecules. From the developmental point of view, the foregut was the common developmental structure of the lung and the large intestine, which suggested that there were similar regulations in the critical biological processes, such as the cellular apoptosis, mutations, communication, proliferation, and differentiation [3, 4]. Besides, the structures of bronchus and intestine were both characterized by the columnar epithelia with goblet cells and submucosal glands, which provided a basis for the development of inflammatory changes in both bronchus or bowel diseases under the same circumstance [5].

In the normal condition, the lung maintains the movement and gas emission of the large intestine by respiratory movement, while the large intestine assisted the lung to conduct proper breathing function [6]. In pathological conditions, the disorders of the lung and the large intestines 
can affect each other. The epidemiological survey showed that lung and large intestine cancers were closely associated with the industrialization and the related factors [7]. Large intestine carcinoma is usually accompanied by cough and shortness of breath because of endo-bronchial metastases [8]. Alveolar leakage and airway inflammation were found during intestinal ischemia by using laser confocal microscope [9]. Similarly, the intestinal permeability was increased in children with asthma [10]. It is reported that $28.5 \%$ of patients with inflammatory bowel diseases had abnormal pulmonary function tests, and $22 \%$ of patients had small airway obstruction or bronchiectasis via high-resolution CT screening [11]. The gut-derived factors contributed to burninduced lung injury and were related to subsequent respiratory failure [12]. In multiple organ dysfunction syndrome (MODS), the digestive tract symptoms often appeared after acute lung injury [13]. The activation of neutrophils in blood released a large number of enzymes and cytokines and caused inflammatory reaction in both lung and large intestine [14], which suggested that active components in the blood circulation and lymphokinesis may contribute to the relationship between the two organs.

A serial of common effector molecules were found in various pathophysiologic conditions in both lung and intestine, such as pulmonary surfactants family, vasoactive intestinal peptide, pulmonary thromboxane A2, sIgA (soluble immunoglobulin A), and cholecystokinin. The pulmonary surfactants played a key role in the evolution of air breathing [15]; however, intestinal surfactants had an earlier origin which could perform a variety of functions after the secretion of enterocyte $[16,17]$. It is reported that the pulmonary surfactant proteins $\mathrm{A}$ and $\mathrm{D}$ were expressed in both pulmonary and gastrointestinal epitheliums [17], which extended the concept of intestinal surfactant and underlined its close relationships with pulmonary surfactant $[18,19]$. It is recognized that the onset of asthma and airway responsiveness were closely associated with decrease of vasoactive intestinal peptide (VIP), which influenced the endogenous oxidant/antioxidant balance and the relaxation of the intestine [20]. Through the release of pulmonary thromboxane A2 (TxA2), intestinal reperfusion induced pulmonary vaso-constriction and increased pulmonary microvascular permeability [21]. After intestinal ischemia and reperfusion, the release of nitric oxide (NO) from the pulmonary vascular endothelium and the airway smooth muscle contraction were impaired, which may contribute to the respiratory failure [22]. The trefoil factor family domain peptides (TFF), responsible for the protection and repair of the intestinal epithelium, were expressed much higher in respiratory tract than in colon tissue and found to be closely associated with lung function [23]. Pathogenic effector Th17 cells were considered to be the common pathogenetic basis in both intestinal and respiratory tracts [24].

The above-mentioned facts provided preliminary scientific evidence for the close relationship between the two organs; however, direct experimental proofs are still lacking. Our study aims to investigate the mutual interactions between the lung and the large intestine by examining the relevancies between the pulmonary functions and the rectal resting pressure in the rat models of asthma and constipation, evaluate the effects of the lung homogenate and the large intestine homogenate on the isolated large intestine muscle strip and the isolated tracheal spiral, respectively, which could provide not only solid experimental evidence for the special relationship between lung and large intestine but also clues for solving complex clinical problems.

\section{Method}

2.1. Animals. Male Sprague-Dawley (SD) rats (4 weeks old, 110-130 g, SLAC Laboratory Animal Co. Ltd., Shanghai, China) were raised in a pathogen-free rodent facility and provided with food and water ad libitum. Rats were kept in animal facilities approved by the Shanghai Committee for Accreditation of Laboratory Animal, and the animal experiment conformed to the regulations of the State Science and Technology Commission.

2.2. The Rat Model of Asthma. Rats were randomly divided into two groups ( $n=8$ each): control and asthmatic model groups. The protocol of SD rat model of asthma was described as previously [25]. Briefly, rats were sensitized with $1 \mathrm{mg}$ ovalbumin (OVA) precipitated with $10 \mathrm{mg}$ of aluminum hydroxide gel in $1 \mathrm{~mL}$ normal saline with intraperitoneal injection. The sensitized rats were challenged two weeks later with $1 \mathrm{~mL} / \mathrm{kg}$ of $5 \%$ OVA in normal saline by injection into the external jugular vein over $10 \mathrm{~s}$. Control rats were sensitized and challenged with normal saline instead of OVA.

2.3. The Rat Model of Constipation. Rats were randomly divided into two groups ( $n=8$ each): control and constipation model groups. The protocol of rat model of constipation was modified from Shan et al. [26]. Briefly, after fasting for $24 \mathrm{~h}$ with free access to water, rats were treated with compound diphenoxylate $(10 \mathrm{mg} / \mathrm{kg}$ body weight, once a day, for four days) in $1 \mathrm{~mL}$ normal saline through intragastric administration, and the time of first defecation with the charcoal meal was recorded. Number and weight of feces were recorded $12 \mathrm{~h}$ after the administration. Control rats were treated with normal saline instead of compound diphenoxylate.

\subsection{Measurements of the Pulmonary Functions and the Rectal} Resting Pressure. When measuring the pulmonary function, a rat under anesthesia was placed on a wood plate in the supine position. A heater was controlled pneumotachograph which connected to a differential pressure transducer (600D011, AutoTran, USA) was gently inserted into the trachea, and the tidal flow was determined. To measure transpulmonary pressure, a water-filled tube which coupled to a pressure transducer (PT14MX, Jialong Teaching Equipment, Shanghai) was inserted into the esophagus to the level of the midthorax. The pneumotachograph tidal flow signal was integrated with time to obtain tidal volume, which was continuously recorded for $30 \mathrm{~min}$. The measurement of rectal resting pressure was modified from Hancock [27]. The tube (diameter $=2.5 \mathrm{~mm}$ ) with a balloon at the front end was inserted slowly into anus for $3.5 \mathrm{~cm}$, which connected with 
pressure transducer (PT14MX, Jialong Teaching Equipment, Shanghai). Twenty min after the tube insertion, rectal resting pressure was recorded by the SMUP-B biological signal analysis system for $30 \mathrm{~min}$.

\subsection{The Preparation of the Tissue Homogenates. After rats} were sacrificed, the lung (including trachea), heart, small intestine (total ileum), and large intestine (total colon) were taken out quickly and respectively. After washing with normal saline and removal of fat, the tissues were weighed and mixed with normal saline at the ratio of $1: 4$. By using electric glass homogenizer machine in ice bath, the tissues were turned into homogenates. After centrifugation at $3500 \mathrm{r} / \mathrm{min}$ for $20 \mathrm{~min}$, the supernatants were kept. The protein concentrations of the homogenates of the lung, heart, large intestine and small intestine, were all adjusted to $5 \mathrm{mg} / \mathrm{mL}, \mathrm{BSA}(5 \mathrm{mg} / \mathrm{mL})$ and normal saline were served as control.

2.6. The Preparation of the Tracheal Spiral and the Large Intestine Muscle Strip. The trachea and large intestine were immediately removed after the sacrifice of rats. The adherent connective tissue and fat on the surface were all removed, and the tissues were put into a Petri dish full of Krebs'-Henseleit $(\mathrm{KH})$ solution $\left(\mathrm{NaCl} 118.0 \mathrm{mmol} / \mathrm{L} ; \mathrm{KCl} 4.7 \mathrm{mmol} / \mathrm{L} ; \mathrm{CaCl}_{2}\right.$ $2.5 \mathrm{mmol} / \mathrm{L} ; \mathrm{MgSO}_{4} 1.2 \mathrm{mmol} / \mathrm{L} ; \mathrm{NaHCO}_{3} 25.0 \mathrm{mmol} / \mathrm{L}$; $\mathrm{KH}_{2} \mathrm{PO}_{4} 1.2 \mathrm{mmol} / \mathrm{L}$; glucose $10.0 \mathrm{mmol} / \mathrm{L}$ ). A tracheal segment (approximately $20 \mathrm{~mm}$ in length from thyroid cartilage to bifurcation of tracheas) was isolated and then suspended in a $80 \mathrm{~mL}$ organ bath by two stainless-steel wires $(0.3 \mathrm{~mm}$ diameter). The $2.5 \mathrm{~cm}$ long large intestine was quickly cut (20 mm away from the lower end of the cecum). One end was fixed to the bottom of the organ bath, whereas the other was connected to the pressure transducer (PT14MX, Jialong Teaching Equipment, Shanghai) for the measurement of isometric tension. The tracheal spiral and the large intestine muscle strip were set up vertically under a tension of $1.5 \mathrm{~g}$, which were maintained in the $\mathrm{KH}$ solution. The organ bath was kept at $37.0 \pm 0.5^{\circ} \mathrm{C}$ and continuously gassed with $95 \% \mathrm{O}_{2}$ and $5 \% \mathrm{CO}_{2}$. The measurement of the isometric tension was recorded, and the tension changed in $10 \mathrm{~min}$ was analyzed. Each tracheal spiral and large intestine muscle strip were used only one time.

2.7. Data Analysis. All data are expressed as the mean \pm SD. The Student's $t$-test was used to analyze the significance of the pulmonary resistance, the pulmonary compliance, and the rectal resting pressure between the two groups in vivo. The relationship between two variables was identified by the linear regression analysis. One-way ANOVA (analysis of variance) followed by the least significant difference (LSD) test for post hoc analysis was used to analyze the significance of tension among the different groups in vitro. The $P$ value that was lower than 0.05 was considered significant.

\section{Results}

3.1. The Pulmonary Functions Were Closely Related to Rectal Resting Pressure in the Rat Models of Asthma and Constipation.
There was no significant relationship between rectal resting pressure and pulmonary resistance in the control rat within $30 \min (r=-0.032, P>0.05)$, and there was also no significant relationship between rectal resting pressure and pulmonary compliance within $30 \mathrm{~min}(r=-0.050, P>$ $0.05)$. In asthmatic rat, the pulmonary resistance was significantly increased at 3-7 $\min (P<0.05$, Table 1$)$; the pulmonary compliance was significantly decreased at 3-10 $\mathrm{min}$ $(P<0.05)$, which suggested the successful establishment of asthma model. There was a significant difference in the rectal resting pressure at $2 \mathrm{~min}$ between the asthmatic model and the control group $(P<0.05)$. Three to seven min after OVA challenge, the rectal resting pressure was decreased and had a negative relationship with pulmonary resistance within 30 min $(r=-0.423, P<0.05)$. Meanwhile, the rectal resting pressure has a positive relationship with pulmonary compliance within $30 \mathrm{~min}(r=0.711, P<0.05)$, which demonstrated that the changes of the pulmonary resistance and pulmonary compliance were closely associated with the level of the rectal resting pressure in the asthmatic model.

Twelve $h$ after compound diphenoxylate administration, the number of stool of rats was significantly decreased by $77.23 \%$ when compared to that of the control group $(P<$ 0.05 ). The weight of stool was significantly decreased in rats in the group of compound diphenoxylate administration by $76.01 \%(P<0.05)$, which suggested the successful establishment of the constipation model. There was no significant difference in the rectal resting pressure between the constipation model and the control group in $10 \mathrm{~min}(P>$ 0.05 ), although the rectal resting pressure of the constipation rats had a tendency to decrease. The pulmonary resistance had a tendency to increase $(P>0.05)$ but had no significant relationship with the rectal resting pressure within $30 \mathrm{~min}$ $(r=0.063, P>0.05)$. However, the pulmonary compliance of the constipation model was significantly decreased at 1-2, $4-7$, and $9-10 \min (P<0.05$, Table 2$)$ and had a significant positive relationship with the rectal resting pressure within 30 min $(r=0.663, P<0.05)$, which suggested that the constipation and the breath difficulty happened at the same time, and the change of the pulmonary compliance was closely associated with the level of the rectal resting pressure in the constipation model.

3.2. Measurements of the Isometric Tensions. The different levels of the acetyl choline (Ach) were used to test the contractive effect on the isolated large intestine muscle strip and the isolated tracheal spiral, and the $70 \%-75 \%$ of the maximal contractile response was chosen and examined in order to avoid the maximum of the concentration response and allow for adequate extension [28]. In the study, the addition of $0.02 \mathrm{mg} / \mathrm{L}$ and $20 \mathrm{mg} / \mathrm{L}$ Ach produced $70 \%-75 \%$ of the maximum contraction of the isolated large intestine muscle strip and the isolated tracheal spiral, respectively, which suggested the successful establishment of the in vitro testing system and demonstrated that the sensitivity of isolated large intestine muscle strip was about 1000 times higher than that of the isolated tracheal spiral.

Different volumes of the tissue homogenates were added separately into the bath of the large intestine muscle strip, 


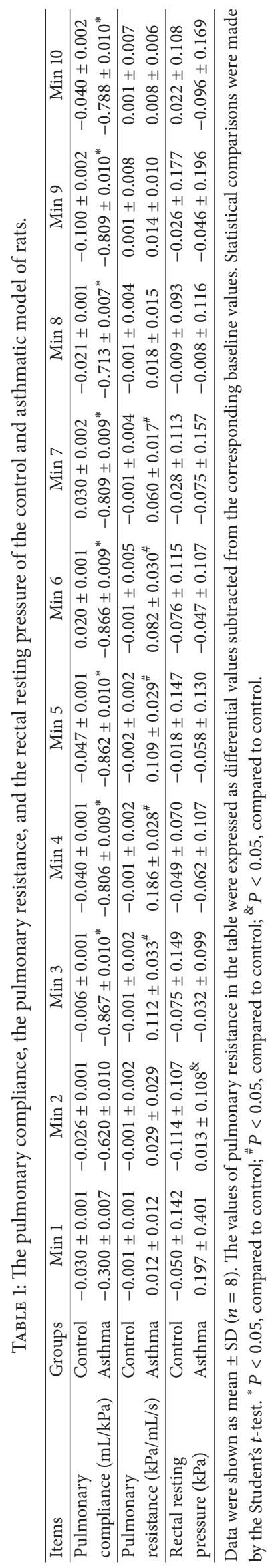




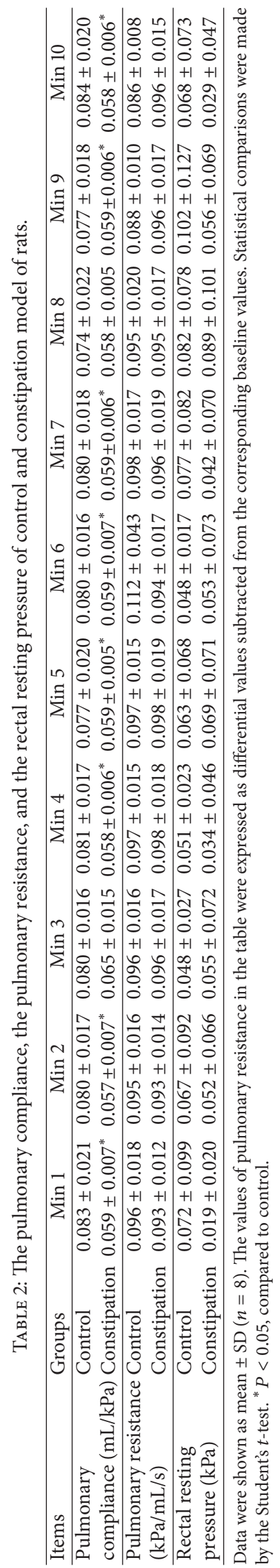




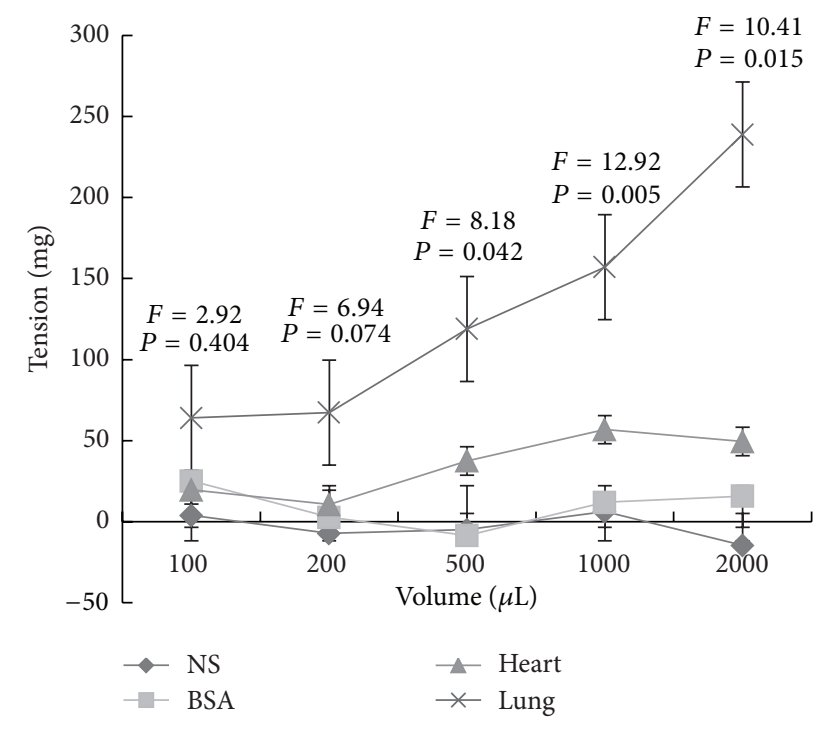

FIGURE 1: The effects of the lung homogenate, the heart homogenate, BSA, and normal saline on the isolated large intestine muscle strip. The addition of $100,200,500,1000$, and $2000 \mu \mathrm{L}$ of the $5 \mathrm{mg} / \mathrm{mL}$ lung homogenate, heart homogenate, BSA, and normal saline into the in vitro testing system of the isolated large intestine muscle strip. The addition of the lung homogenate could significantly contract the isolated large intestine muscle strip at the volume of 500, 1000, and $2000 \mu \mathrm{L}(P<0.05)$.

and, with the increase of the volume, the contraction response was recorded. The addition of the 100, 200, 500, 1000, and $2000 \mu \mathrm{L}$ of the $5 \mathrm{mg} / \mathrm{mL}$ heart homogenate, BSA, and normal saline had no significant effects on the isolated large intestine muscle strip $(P>0.05$, Figure 1$)$; however, the addition of 500,1000 , and $2000 \mu \mathrm{L}$ of the $5 \mathrm{mg} / \mathrm{mL}$ lung homogenate could significantly contract the isolated large intestine muscle strip $(P<0.05)$, which demonstrated the special effect of lung homogenate on the isolated large intestine muscle strip. In the group of 500 and $1000 \mu \mathrm{L}$ addition, the tension induced by the lung homogenate was 3.1 and 2.8 times greater than that of the heart homogenate $(P<0.05)$. In the group of $2000 \mu \mathrm{L}$ addition, the tension induced by the lung homogenate was the maximal and 4.8 time greater than that of the heart homogenate $(P<0.05)$.

The addition of the $100,200,500,1000$, and $2000 \mu \mathrm{L}$ of the $5 \mathrm{mg} / \mathrm{mL}$ large intestine homogenate, small intestine homogenate, BSA, and normal saline had no significant effects $(P>0.05$, Figure 2$)$ on the isolated tracheal spiral, which may be due to the low sensitivity of the isolated tracheal spiral.

\section{Discussion}

The data showed that the pulmonary resistance and pulmonary compliance were closely related to the rectal resting pressure in asthmatic rat model, and the rectal resting pressure was closely associated with pulmonary resistance in the rat model of constipation. The lung homogenate could specifically contract the isolated large intestine muscle strip in

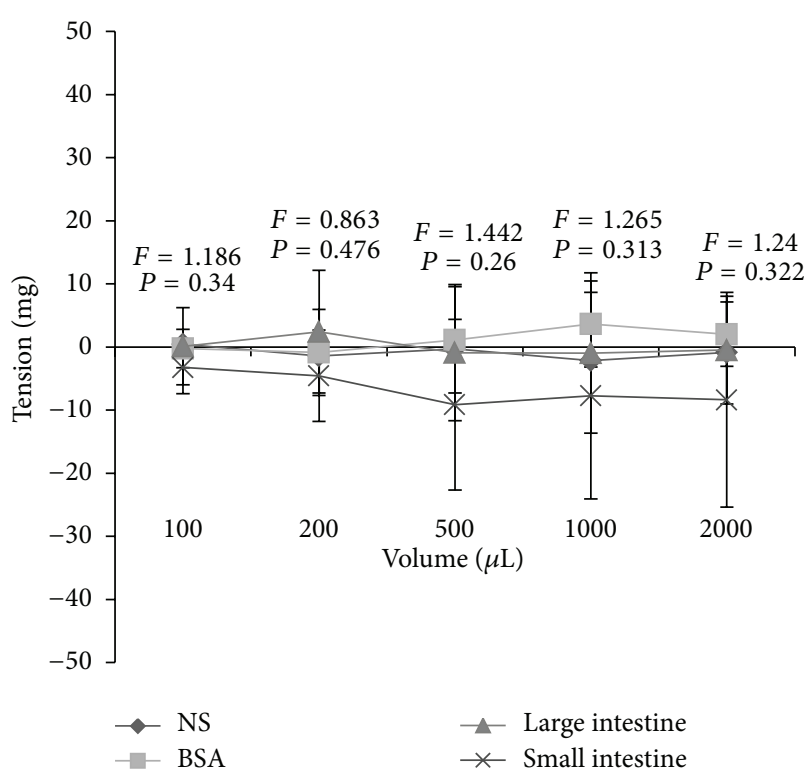

FIGURE 2: The effects of the large intestine homogenate, the small intestine homogenate, BSA, and normal saline on the isolated tracheal spiral. The addition of the 100, 200, 500, 1000, and $2000 \mu \mathrm{L}$ of the $5 \mathrm{mg} / \mathrm{mL}$ large intestine homogenate, small intestine homogenate, BSA, and normal saline had no significant effects $(P>$ $0.05)$ on the isolated tracheal spiral.

vitro. These results suggested that the lung and large intestine had a specific relationship between each other, which may provide clues for a further study.

The common active proteins and the corresponding receptors, such as sIgA and cholecystokinin, may account for the underlying mechanism of lung and large intestine mutual interaction. sIgA exists specifically in both lung and intestinal tissues and is considered to be the common mucosal immune molecules base [29]. The polymeric immunoglobulin receptors for IgA were also found expressed in lung, bronchi, gut, and so on, which was involved not only in the antigenantibody complex recognition but also in various signal transduction under different conditions [30]. Another important neuropeptide cholecystokinin (CCK), which is expressed in the gastrointestinal nervous system, was now found widely distributed in trachea and alveoli [31]. CCK played a role in protecting gastric mucosa and stimulating the digestion of nutrition, and now totally two types of CCK receptors have been identified [32]. Recent studies have reported that the sIgA and CCK and their corresponding receptors may be closely associated with the specific relationship between the lung and large intestine. It is reported that the CCK2 receptor with retention of intron 4 (CCK2Ri4sv) was now a marker of specific gastrointestinal and lung tumors [33]. In CCR3 knockout mice model, the eosinophil recruitment in the lung was decreased while the number of intraepithelial mast cells was increased in the trachea after OVA sensitization and allergen challenge [34]. Study demonstrated that the expression of CCK receptors and cytokine productions on peripheral blood and bronchoalveolar lavage fluid (BALF) in asthma patients were significantly increased [35]. Modern 
research has confirmed that both the lung and large intestine were endocrine organs and could synthesize a serial of active substances when receiving signals from the internal and external environments. Ovalbumin (OVA) is widely used as a reference allergen to induce allergic asthma, which can cause the imbalance of CD4+ T lymphocytes, secretion of cytokines, and immune inflammation [36]. In our rat model of OVA-induced asthma, the expressions of immunerelated proteins, like sIgA and CCK, could be changed in asthmatic lung; meanwhile the corresponding receptors were subsequently altered in the large intestine; in this way the pathological condition of lung may influence the status of large intestine and vice versa.

The intestine muscle strip is frequently used as an evaluation tool for the intestinal smooth muscle function, and the behavior of the intestines varies among different species. It is showed that the $0.01 \mathrm{mg} / \mathrm{L}$ Ach evoked the contraction of human colon [37], which was two times more sensitive than that of the rat intestine. The level of $0.03 \mathrm{mg} / \mathrm{L}$ Ach caused the contraction of the longitudinal muscle strip which was obtained from guinea pig ileum [38]. It is reported that 0.1$10 \mathrm{mg} / \mathrm{L}$ Ach contracted the longitudinal and circular muscle strips of rabbit while $0.1 \mathrm{mg} / \mathrm{L}$ atropine blocked the effect of $10 \mathrm{mg} / \mathrm{L}$ Ach [39]. In our large intestine muscle strip of rat, the level of $0.02 \mathrm{mg} / \mathrm{L}$ Ach caused about $70 \%-75 \%$ of the maximum contraction, and this data was consistent with the previous studies, which provided a suitable testing system for the in vitro research.

A serial of pharmacological agents have been tested in the model of the intestine muscle strip. It is reported that the 10-50 $\mu \mathrm{m}$ ATP transmural stimulation caused relaxations of the rat duodenum and ileum [40]. Exogenous addition of $20 \mathrm{ng} / \mathrm{mL}$ IL- 6 increased the contraction of the circular muscle strip of colon and suggested that the contraction induced by IL- 6 may be due to the acting on the gut's nervous system [41]. As an antagonist of the muscarinic receptors, MB327 showed a fully reversible smooth muscle relaxing effect at lower concentrations in a rat jejunum smooth muscle model [42]. In our in vitro study, the addition of the lung homogenate contracted specially the isolated large intestine muscle strip, which suggested that the lung homogenate might contain active proteins that could bind to the corresponding receptors in the large intestine and carried out biological functions. Besides, it is also known that the interstitial cells, such as smooth muscle cells and the interstitial cell of Cajal (ICC), could release Ach by transmural stimuli and the activation of the cholinergic fibers $[43,44]$. In our study, the addition of tissue homogenates may induce a small amount of Ach release of the large intestine and lead to the contraction. The study provided a foundation for further research, and, if a specific protein and receptor could be well identified in the future, it may contribute to the medical science and well reflect the biological value of traditional Chinese medicine.

\section{Conclusion}

In the current study, we showed that the changes of the pulmonary functions were closely related to the rectal resting pressure in the rat models of asthma and constipation, and the lung homogenate could significantly contract the large intestine muscle strip. It provided new lines of evidence for the "exterior-interior relationship between the lung and the large intestine" and highlighted the use of this theory in the treatment of the corresponding diseases in the future.

\section{Conflict of Interests}

The authors have declared that no competing interests exist.

\section{Authors' Contribution}

Lei-Miao Yin and Guang-Quan Zhang contributed equally to this work.

\section{Acknowledgments}

This work was supported by the National Natural Science Foundation of China (nos. 81001548, 81173341, 81173332, and 81202753) and Shanghai Rising-Star Program (12QA1403000).

\section{References}

[1] G. Maciocia, The Foundations of Chinese Medicine, Churchill Livingstone, Edinburgh, UK, 2005.

[2] B. Liu, J. Wang, and J.-P. Zhao, "Intermediate structure of the interior-exterior relationship between lung and large intestine," Zhongguo Zhen Jiu, vol. 31, no. 4, pp. 363-365, 2011.

[3] S. Faure and P. de Santa Barbara, "Molecular embryology of the foregut," Journal of Pediatric Gastroenterology and Nutrition, vol. 52, no. 1, pp. S2-S3, 2011.

[4] A. M. Zorn and J. M. Wells, "Vertebrate endoderm development and organ formation," Annual Review of Cell and Developmental Biology, vol. 25, no. 1, pp. 221-251, 2009.

[5] T. Higenbottam, G. M. Cochrane, T. J. H. Clark, D. Turner, R. Millis, and W. Seymour, "Bronchial disease in ulcerative colitis," Thorax, vol. 35, no. 8, pp. 581-585, 1980.

[6] W. E. Arnould-taylor, A Textbook of Anatomy and Physiology, Nelson Thornes, Cheltenham, UK, 1998.

[7] M. Murata, K. Takayama, S. Fukuma et al., "A comparative epidemiologic study on geographic distributions of cancers of the lung and the large intestine in Japan," Japanese Journal of Cancer Research, vol. 79, no. 9, pp. 1005-1016, 1988.

[8] B. W. Carlin, J. H. Harrell II, L. K. Olson, and K. M. Moser, "Endobronchial metastases due to colorectal carcinoma," Chest, vol. 96, no. 5, pp. 1110-1114, 1989.

[9] H. Mitsuoka, T. Sakurai, N. Unno et al., "Intravital laser confocal microscopy of pulmonary edema resulting from intestinal ischemia-reperfusion injury in the rat," Critical Care Medicine, vol. 27, no. 9, pp. 1862-1868, 1999.

[10] Z. Hijazi, A. M. Molla, H. Al-Habashi, W. M. R. A. Muawad, A. M. Mollo, and P. N. Sharma, "Intestinal permeability is increased in bronchial asthma," Archives of Disease in Childhood, vol. 89, no. 3, pp. 227-229, 2004.

[11] D. Desai, S. Patil, Z. Udwadia, S. Maheshwari, P. Abraham, and A. Joshi, "Pulmonary manifestations in inflammatory bowel disease: a prospective study," Indian Journal of Gastroenterology, vol. 30, no. 5, pp. 225-228, 2011. 
[12] L. J. Magnotti, D.-Z. Xu, Q. Lu, and E. A. Deitch, "Gutderived mesenteric lymph: a link between burn and lung injury," Archives of Surgery, vol. 134, no. 12, pp. 1333-1341, 1999.

[13] E. D. Crouser and P. M. Dorinsky, "Gastrointestinal tract dysfunction in critical illness: pathophysiology and interaction with acute lung injury in adult respiratory distress syndrome/multiple organ dysfunction syndrome," New Horizons, vol. 2, no. 4, pp. 476-487, 1994.

[14] K. Brown, S. Brain, J. Pearson, J. Edgeworth, S. Lewis, and D. Treacher, "Neutrophils in development of multiple organ failure in sepsis," The Lancet, vol. 368, no. 9530, pp. 157-169, 2006.

[15] C. B. Daniels and S. Orgeig, "Pulmonary surfactant: the key to the evolution of air breathing," News in Physiological Sciences, vol. 18, no. 4, pp. 151-157, 2003.

[16] A. Turan, S. Gupta, and A. Mahmood, "Characteristics and physiological role of surfactant-like particles secreted by entrocytes," Indian Journal of Experimental Biology, vol. 44, no. 7, pp. 519-525, 2006.

[17] J. R. Bourbon and B. Chailley-Heu, "Surfactant proteins in the digestive tract, mesentery, and other organs: evolutionary significance," Comparative Biochemistry and Physiology, vol. 129, no. 1, pp. 151-161, 2001.

[18] S. Rubio, T. Lacaze-Masmonteil, B. Chailley-Heu, A. Kahn, J. R. Bourbon, and R. Ducroc, "Pulmonary surfactant protein A (SPA) is expressed by epithelial cells of small and large intestine," Journal of Biological Chemistry, vol. 270, no. 20, pp. 12162-12169, 1995.

[19] Z. Lin and J. Floros, "Heterogeneous allele expression of pulmonary SP-D gene in rat large intestine and other tissues," Physiological Genomics, vol. 11, pp. 235-243, 2003.

[20] A. M. Szema, S. A. Hamidi, A. Koller, and D. W. Martin, "Vasoactive Intestinal Peptide Knockout (VIP KO) mouse model of sulfite-sensitive asthma: up-regulation of novel lung carbonyl reductase," BMC Immunology, vol. 12, article no. 66, 2011.

[21] R. H. Turnage, J. L. Lanoue, K. M. Kadesky, Y. Meng, and S. I. Myers, "Thromboxane A2 mediates increased pulmonary microvascular permeability after intestinal reperfusion," Journal of Applied Physiology, vol. 82, no. 2, pp. 592-598, 1997.

[22] C. Köksoy, M. A. Kuzu, H. Ergün, E. Demirpençe, and B. Zülfikaroglu, "Intestinal ischemia and reperfusion impairs vasomotor functions of pulmonary vascular bed," Annals of Surgery, vol. 231, no. 1, pp. 105-111, 2000.

[23] E. dos Santos Silva, M. Ulrich, G. Doring, K. Botzenhart, and P. Gott, "Trefoil factor family domain peptides in the human respiratory tract," Journal of Pathology, vol. 190, no. 2, pp. 133142,2000

[24] C. T. Weaver, C. O. Elson, L. A. Fouser, and J. K. Kolls, “The Th17 pathway and inflammatory diseases of the intestines, lungs, and skin," Annual Review of Pathology, vol. 8, pp. 477-512, 2013.

[25] L.-M. Yin, G.-H. Jiang, Y. Wang et al., "Serial analysis of gene expression in a rat lung model of asthma," Respirology, vol. 13, no. 7, pp. 972-982, 2008.

[26] J. J. Shan, Y. Zhang, Y. L. Diao, W. S. Qu, and X. N. Zhao, "Effect of an antidiabetic polysaccharide from Inula japonica on constipation in normal and two models of experimental constipated mice," Phytotherapy Research, vol. 24, no. 11, pp. 1734-1738, 2010.

[27] B. D. Hancock, "Measurement of anal pressure and motility," Gut, vol. 17, no. 8, pp. 645-651, 1976.
[28] L.-M. Yin, H.-Y. Li, Q.-H. Zhang et al., "Effects of S100A9 in a rat model of asthma and in isolated tracheal spirals," Biochemical and Biophysical Research Communications, vol. 398, no. 3, pp. 547-552, 2010.

[29] B. Corthésy, "Roundtrip ticket for secretory IgA: role in mucosal homeostasis?" Journal of Immunology, vol. 178, no. 1, pp. 27-32, 2007.

[30] C. Pilette, Y. Ouadrhiri, V. Godding, J.-P. Vaerman, and Y. Sibille, "Lung mucosal immunity: immunoglobulin: a revisited," European Respiratory Journal, vol. 18, no. 3, pp. 571-588, 2001.

[31] F. Noble, S. A. Wank, J. N. Crawley et al., "International union of pharmacology. XXI. Structure, distribution, and functions of cholecystokinin receptors," Pharmacological Reviews, vol. 51, no. 4, pp. 745-781, 1999.

[32] M. Dufresne, C. Seva, and D. Fourmy, "Cholecystokinin and gastrin receptors," Physiological Reviews, vol. 86, no. 3, pp. 805847, 2006.

[33] M. Körner, B. Waser, J. C. Reubi, and L. J. Miller, “CCK2 receptor splice variant with intron 4 retention in human gastrointestinal and lung tumours," Journal of Cellular and Molecular Medicine, vol. 14, no. 4, pp. 933-943, 2010.

[34] A. A. Humbles, B. Lu, D. S. Friend et al., "The murine CCR3 receptor regulates both the role of eosinophils and mast cells in allergen-induced airway inflammation and hyperresponsiveness," Proceedings of the National Academy of Sciences of the United States of America, vol. 99, no. 3, pp. 1479-1484, 2002.

[35] A. J. Morgan, F. A. Symon, M. A. Berry, I. D. Pavord, C. J. Corrigan, and A. J. Wardlaw, "IL-4-expressing bronchoalveolar T cells from asthmatic and healthy subjects preferentially express CCR3 and CCR4," Journal of Allergy and Clinical Immunology, vol. 116, no. 3, pp. 594-600, 2005.

[36] R. K. Kumar, C. Herbert, and P. S. Foster, "The "classical" ovalbumin challenge model of asthma in mice," Current Drug Targets, vol. 9, no. 6, pp. 485-494, 2008.

[37] D. J. Fishlock and A. G. Parks, "A study of human colonic muscle in vitro," British Medical Journal, vol. 2, no. 5358, pp. 666-667, 1963.

[38] W. D. Paton and M. A. Zar, "The origin of acetylcholine released from guinea-pig intestine and longitudinal muscle strips," Journal of Physiology, vol. 194, no. 1, pp. 13-33, 1968.

[39] M. Gallacher, B. R. Mackenna, and H. C. McKirdy, "Effects of drugs and of electrical stimulation on the muscularis mucosae of rabbit large intestine," British Journal of Pharmacology, vol. 47, no. 4, pp. 760-764, 1973.

[40] G. Burnstock, D. G. Satchell, and A. Smythe, "A comparison of the excitatory and inhibitory effects of non-adrenergic, noncholinergic nerve stimulation and exogenously applied ATP on a variety of smooth muscle preparations from different vertebrate species," British Journal of Pharmacology, vol. 46, no. 2, pp. 234-242, 1972.

[41] L. Zhang, L. Hu, M. Chen, and B. Yu, "Exogenous interleukin6 facilitated the contraction of the colon in a depression rat model," Digestive Diseases and Sciences, 2013.

[42] C. Koniger, F. Worek, H. Thiermann, and T. Wille, "Effect of MB327 and oximes on rat intestinal smooth muscle function," Chemico-Biological Interactions, vol. 204, no. 1, pp. 1-5, 2013.

[43] H. M. Cousins, F. R. Edwards, and G. D. S. Hirst, "Neuronally released and applied acetylcholine on the longitudinal muscle of the guinea-pig ileum," Neuroscience, vol. 65, no. 1, pp. 193-207, 1995. 
[44] G. D. S. Hirst and S. M. Ward, "Interstitial cells: involvement in rhythmicity and neural control of gut smooth muscle," Journal of Physiology, vol. 550, no. 2, pp. 337-346, 2003. 


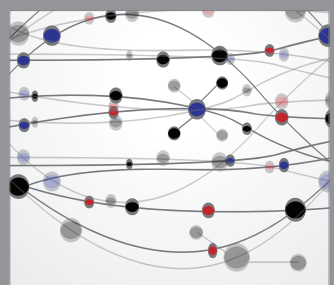

The Scientific World Journal
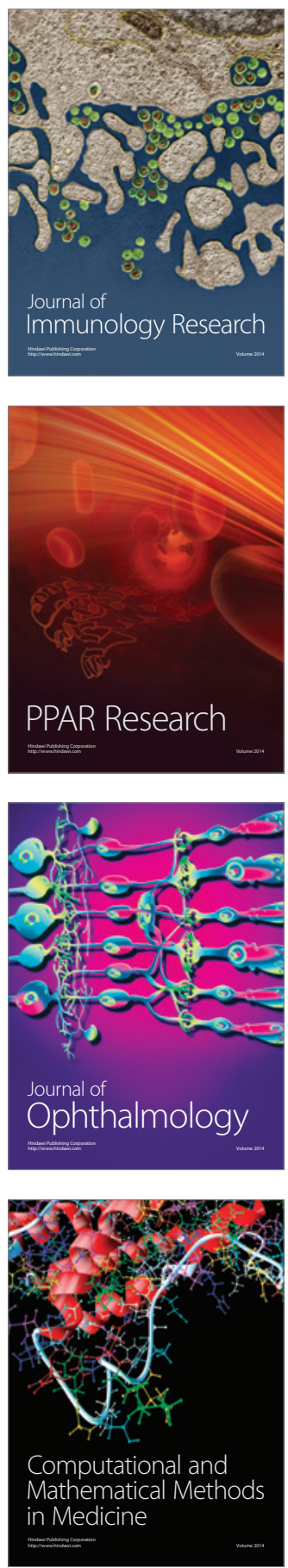

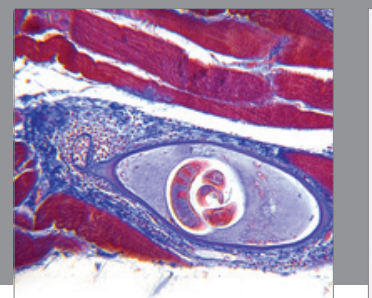

Gastroenterology

Research and Practice
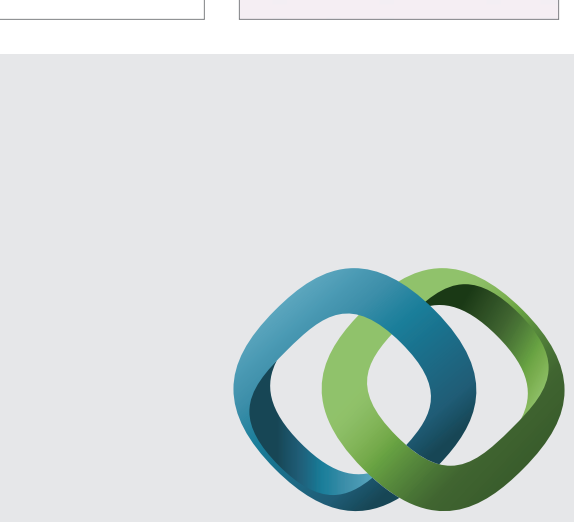

\section{Hindawi}

Submit your manuscripts at

http://www.hindawi.com
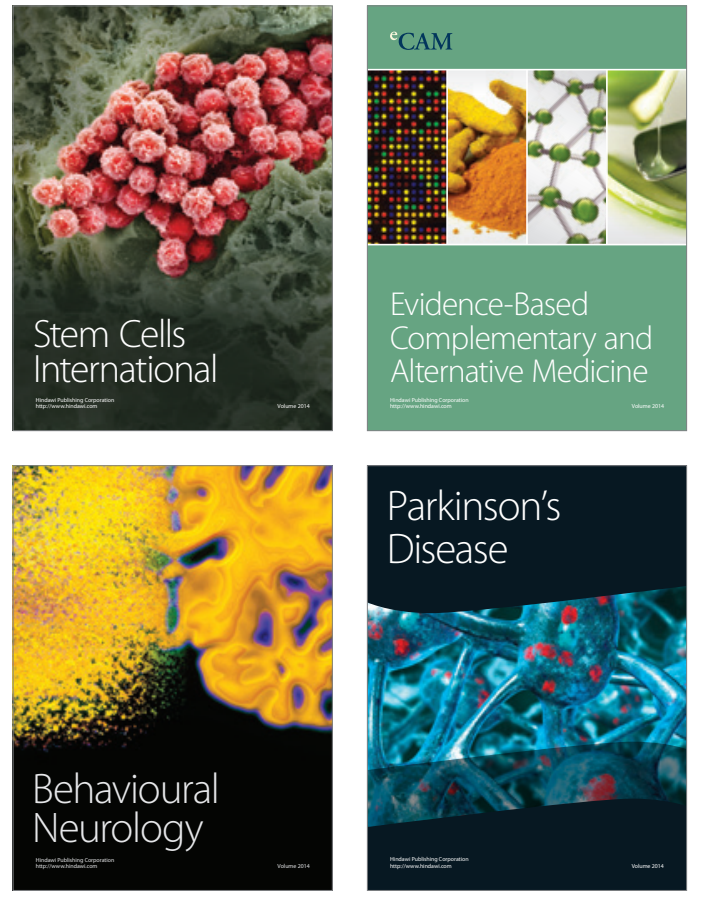
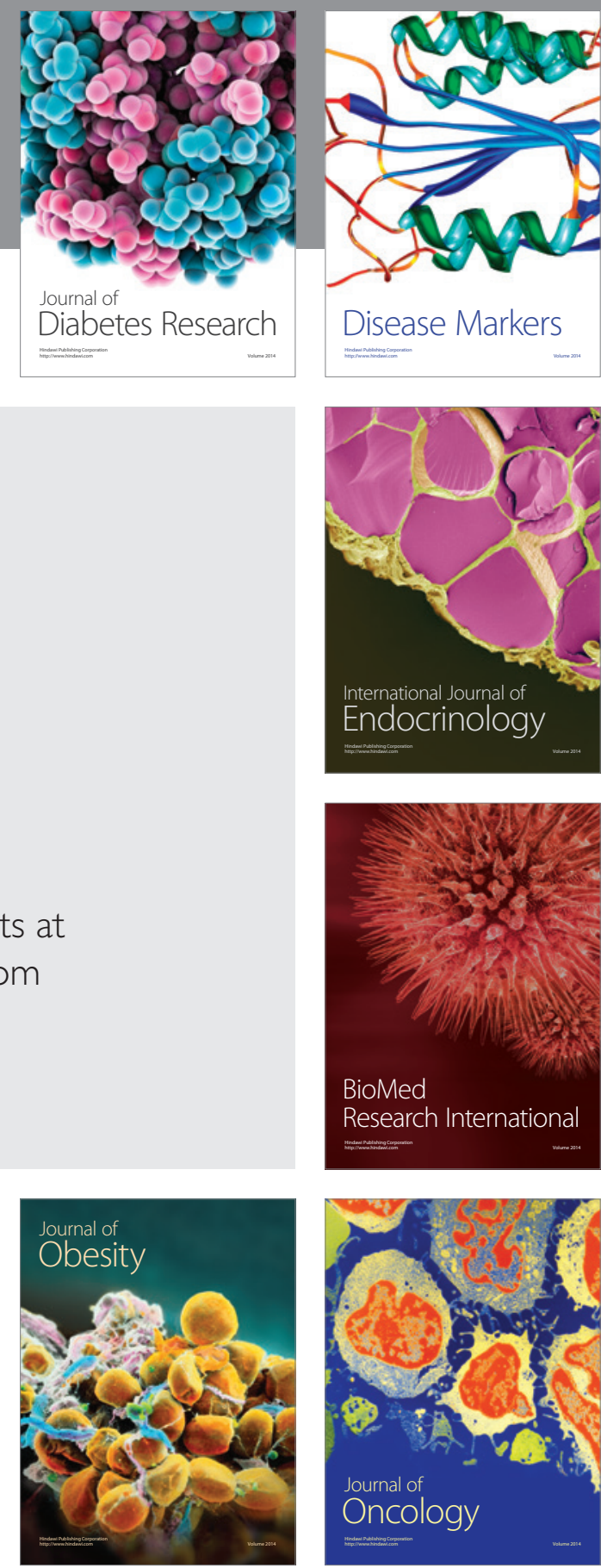

Disease Markers
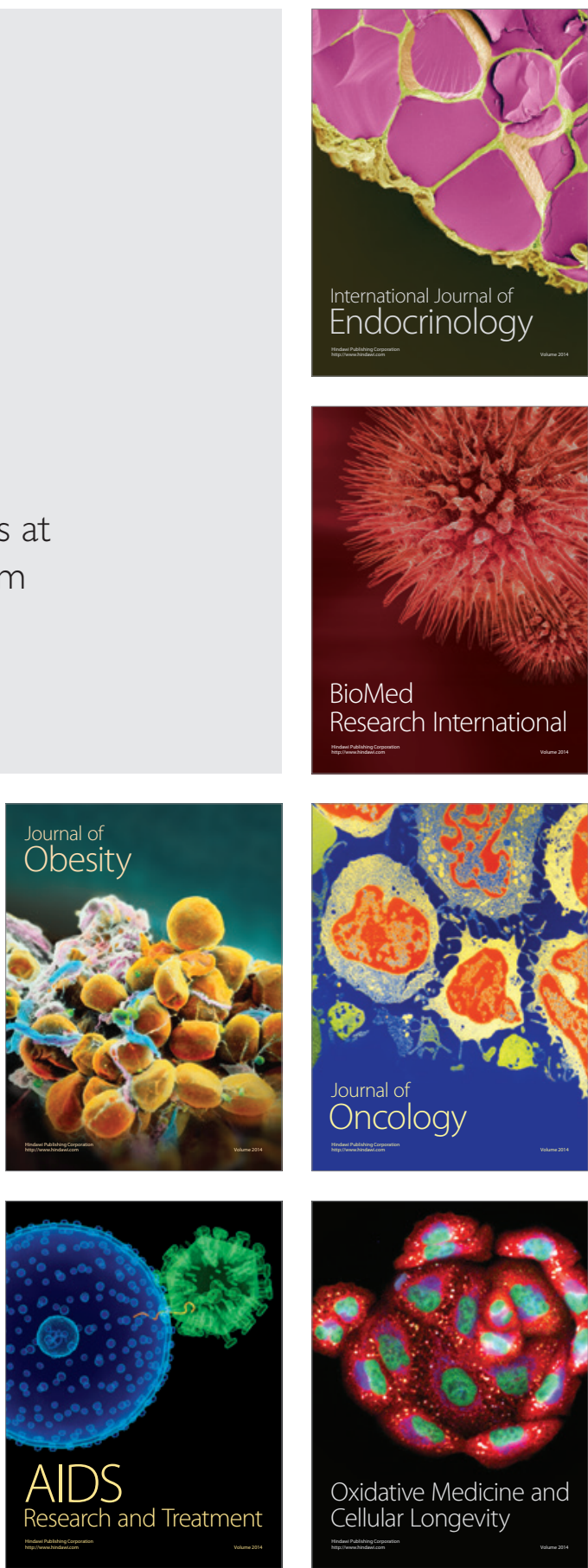